\title{
Learning for an Agile Manufacturing
}

\author{
Heinz-Hermann Erbe \\ Technische Universität Berlin, Institut für Berufliche Bildung,Franklinstrasse 28/29, D-10587 \\ Berlin, Germany \\ Email: heinz.erbe@u-berlin.de
}

\begin{abstract}
Agile Manufacturing is built around the synthesis of a number of independent enterprises forming a network to join their core skills, competencies and capacities to be capable of operating profitably in a competitive environment characterised by unpredictable and continually changing customer demands. Central to the ability to form networks is a cooperative learning of all members of an enterprise. This is an understanding of a learning enterprise. The objective is to produce a solid framework or structure for organisational learning. The introduction of organisational learning in individual as well as networked enterprises in order to prepare for virtual enterprises is discussed. The establishment of continuing improvement of work and learning processes stabilise enterprises and are a precondition for a successful network.
\end{abstract}

Key words: Informal learning, Co-operative work, Networking enterprises

\section{INTRODUCTION}

The environment for enterprises has changed essentially in the nineties. There are various reasons:

- Globalisation, which entails more competition and therefore forces enterprises to become more productive and market-oriented.

- Intensification of cost pressure caused by outsourcing programs of the large-scale enterprises.

- Ever faster changing market-conditions - more flexibility is needed to cope with it.

- Decreasing "time-to-market" time. 
- Turning away from Taylorism and ever faster development of new technologies, which means that enterprises, their owners and employees, have to learn how to work with it and how to maintain flexibility within their organisation to integrate these new technologies.

- In industrialised countries, additional constraints from legislation like taxation and environmental care have increased.

Many enterprises, and particularly small and medium ones, in the United States as well in Europe are affected by these changes. Consequently, many firms not capable of coping with these changes have gone bankruptcy within the last couple of years. The question is therefore how to prepare these enterprises to be strong enough to survive this era of new competitiveness. Why are well-established enterprises failing in spite of innovative ideas for innovative products as well as organisational structures? What can be done to enhance their competitiveness long term?

- It turns out that the only long-term competitive advantage is the capability of enterprises to learn continuously for continuous improvement including management and shop floor in order to become flexible for the changing environment.

- It has shown that flexibility, the ability to cope with and adapt to rapid changing quickly, is a core success factor, which needs to be improved.

- Forming networks of enterprises (extended enterprises) for an agile manufacturing, although they are still independent and competitors.

Agile Manufacturing is understood here as the synthesis of a number of independent enterprises forming a network to join their core skills, competencies and capacities to be capable of operating profitably in a competitive environment of continually, and unpredictable, changing customer demands. They do not own significant capital resources and that will help them to be agile.

Central to the ability of enterprises to form networks is besides trust building among each other and cultural attributes (FREITAG, WINKLER, 2000) the deployment of suitable information and communication technology (ICT) and the deployment of nimble organisational structures to support highly skilled, knowledgeable and empowered People. Networked task processing needs collective competencies. NULLMEIER (1999) discusses how ICT can promote or hamper networking and developing a collective competence. The implementation of information and communication technology top-down do not guarantee for necessary organisational change (BOEKHOFF, ERBE, 1999). However, a prerequisite for networking, supported or not through ITC, is the ability for cooperative work (WEBER, 1999). A collective objectivizing how to solve tasks by team-working, to build a collec- 
tive mental model, is not natural for individuals, and has therefore to be trained, firstly in an individual enterprise. The step to networking cross-border of enterprises is a qualitative leap regarding team-working. The objectivizing of tasks is then mostly not possible face-to-face but instead guided by ITC. Here a suitable ITC platform comes into play together with an organisation preserving the autonomy of the cross-border team. Both can be interpreted as a learning-process, the sculpting of learning networked enterprises as an extension of the well described learning organisation (WATKINS, MARSICK, 1993).

\section{TRANSFORMING TRADITIONAL ORGANISED ENTERPRISES TO AGILE MANUFACTURING IN NETWORKS}

\subsection{Cooperative Work and Learning}

Economy interprets cooperation as all kinds of collaboration in industry and commerce, particularly within the national economy, based on the division of labour. Cooperation aims to increase the competitiveness of different and independent enterprises. Therefore strategic alliances, networks or extended enterprises develop, and in the end, virtual enterprises (SCHUH et al. 1998).

Psychology interprets cooperation as the individual benefit of collaboration and the tasks and objectives enhancing the likelihood of common work.

Sociology stresses the common values and objectives as a presupposition of collaboration and how to organise it. Cooperation can be considered as a benefit maximising, egocentric perspective, or with an aspect of mutual optimising the benefits. GLANCE, HUBERMAN (1993) discuss in this context the dynamics of social dilemmas. Consider a group of friends arranged to meet in a fine restaurant with an unspoken agreement to divide the bill evenly. What do each individual order? Selfishly the best to maximise her benefit or cooperating for the long term common good? It depends of course how often the same group will come together in the future. GLANCE, HUBERMAN (1993) found, with borrowing methods from statistical thermodynamics, a meta-stable equilibrium point when the number of cooperating members in the group is small. When the number increases, a highly unstable situation occurs until it settles in a true equilibrium point. These and further results of their considerations suggest practical ways to restructure organisations, and in particular, networks of small enterprises to secure cooperation. 
WEBER (1999) considers cooperative acting in the context of work and calls it an exchange on equal terms between free and independent individuals. Pro-social acting means the support and encouragement of the other. Mutual representations are considered as indicators of a cooperative willingness to act. The members of a manufacturing team put the existing individual knowledge and the new obtained experiences cooperatively in an objectivized shape when coping with their tasks. Cooperative acting yields in a qualitative leap respecting the work organisation, for the individual as well as for the overall economic result. A collective leeway for planning and decision making, the complexity of a common task and the dependence of the different individually executed jobs, foster a common orientation of the tasks.

Innovation is not only the ability to combine existing experiences, knowledge and technologies effectively in order to develop products and services to put them on the market, but also the ability to change the organisation appropriately to the demands of the market.

Formal as well as informal learning within task-solving is not only to be understood solely as training for each individual staff member but also as a mean to develop the capacity for innovations within the organisation.

Continuous innovation requires a continuing education, continuing learning - this is where the leaning organisation comes into play. Not only at the management level one has to learn continuously, at the shop floor level this continuous learning is particularly important, particularly as the knowledge about the manufacturing technology is present here.

The following aspects have to be considered: actually there is individual learning (formal and informal, Figure 1), but how to shift to organisational learning and further to get from organisational learning to a "network-learning"? The subjects of learning are the individuals in an enterprise; organisational learning is a qualitative leap from individual learning: it is the ability of an organisation or enterprise to gain insight and understanding from experience through experimentation, observation, analysis, and a willingness to examine both successes and failures.

Learning in Organisations (SENGE 1990; WATKINS, MARSICK 1993) suggests an improvement of the learning environment, a delegation of competencies nowadays owned by the management. Furthermore, responsibilities have to be delegated in order to achieve more flexibility and to improve the quality of processes, products and services.

Attempts to implement such environments have been already tried, but (almost) exclusively in big international companies (YORKS et al. 1999), whereas the small enterprises often are financially unable to afford consulting services. 


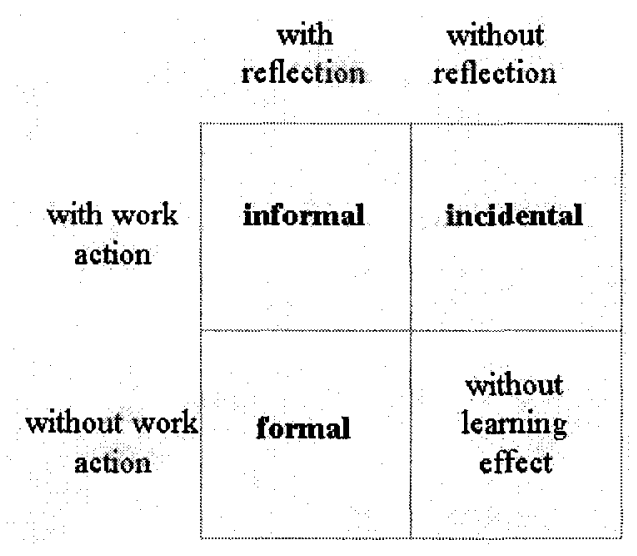

Figure 1. General aspects of learning

Figure 2 defines learning steps inside an individual enterprise. These steps were carried out in a small enterprise of model-making for sand casting. The challenge was to cope with new customer demands on sophisticated model-making using CAD-data the customer would transmit on-line. New workers trained for working with CAD-data and numerically controlled machines had to be integrated into the existing workforce of highly experienced handicraft model makers. Therefore one decided to learn for a cooperative work. A facilitator from outside fostered the learning process inside the enterprise (ERBE, KIM 1998).

Not only here but mostly in enterprises after some time the question arises: How to keep the knowledge and experience at the shop floor level? The current problem is that incentives within enterprises are forcing good and skilled workers to move vertically in the organisational structure, which means they are "encouraged" to leave the shop floor level. But since the view is taken that innovations need to take place at the shop floor level, these employees need incentives to stay.

\subsection{Cooperative Work in Customer-Supplier-Networks}

Networks between suppliers and between suppliers and customers should be designed as platforms, not as chains. A part of a chain can break and destroy or severely damage the whole network. The metaphor "platform" means that all enterprises in the network have access to all relevant information, regarding the order of a customer, the work-capacities of the partners in the network and their specific core competencies in order to discuss the distribution of tasks accordingly. 


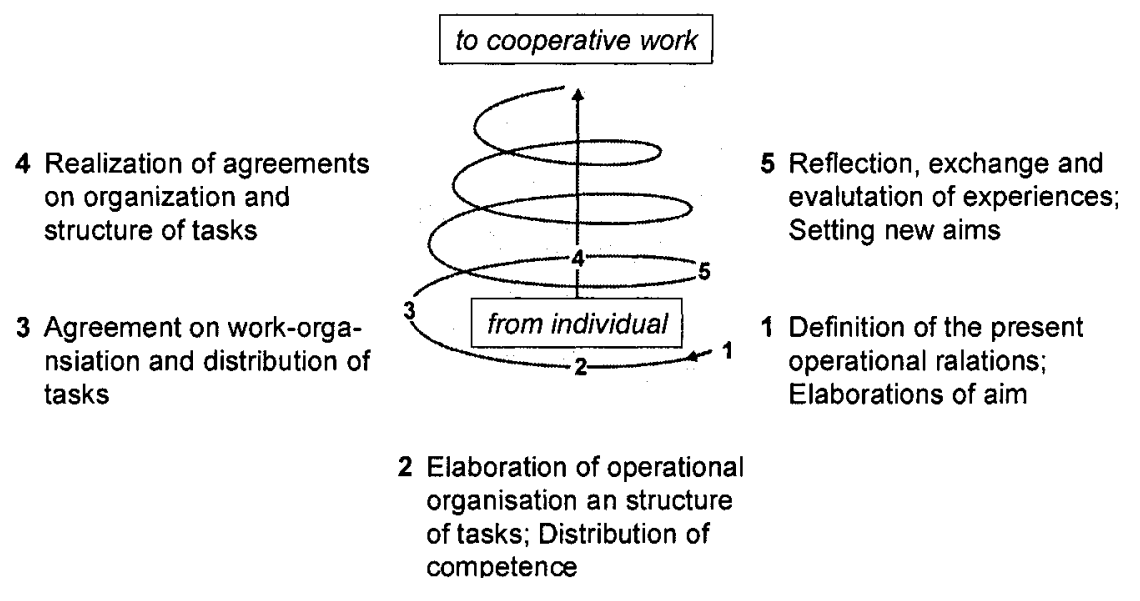

Figure 2. Learning steps from individual to cooperative work of management and shop floor members of an individual enterprise

(Source: ERBE 2003, p. 270)

At first the management of the individual enterprises have to understand or to analyse the advantages and/or disadvantages of networks. Secondly they have to understand that all personnel of the enterprise have to be involved. Then, a lot of mental barriers must be overcome in order to make networks work effectively. Learning processes have to be developed wherein all employees are involved. It needs to be found how this will effectively work in view of the particular conditions confronting small enterprises.

Respecting customer orders not all partners are necessarily involved in processing them. That depends on the particular order regarding capacities and special equipment available. Therefore sometimes only few enterprises of the network are generating a "virtual" enterprise for processing the customer order. Figure 3 illustrates the generation and dissolution of a virtual enterprise based on a stable platform of networked enterprises (SCHUH et al. 1998).

The virtual enterprise executes cooperatively the tasks belonging to the order of a customer, respecting the core competencies of the networked enterprises and using computer networks of information and communication technology. These technologies should be customised to the specific needs in networks. CAMARINHA-MATOS, AFSARMANESH (2000) discuss cooperative systems as a set of autonomous agents (computational and human) interacting which each other "through sharing their information, decision making capabilities and other resources, and distributing the corresponding workload among themselves, in order to achieve common or complementary goals". They emphasise the social and organisational issues and their conse- 
quences at technical levels, the importance to identify the consequences in terms of the working structure, the processes and the roles played by all social intervening actors. As small and medium sized enterprises are characterised "by a strong human-centred decision making philosophy, strong feelings of autonomy and information privacy" it is the challenge to overcome these cultural attributes to a new culture of willingness to build confidence and "a new idea of ownership that goes beyond the borders" of each participating enterprise within the network. BOEKHOFF, ERBE (1999) stress, that besides the implementation of technology, the success of an enterprise and networks as well, is determined mainly through the capability of management and workforce for cooperative work. It is a misunderstanding to assume that technology is an external force that would have deterministic impacts on organisational properties and structure.

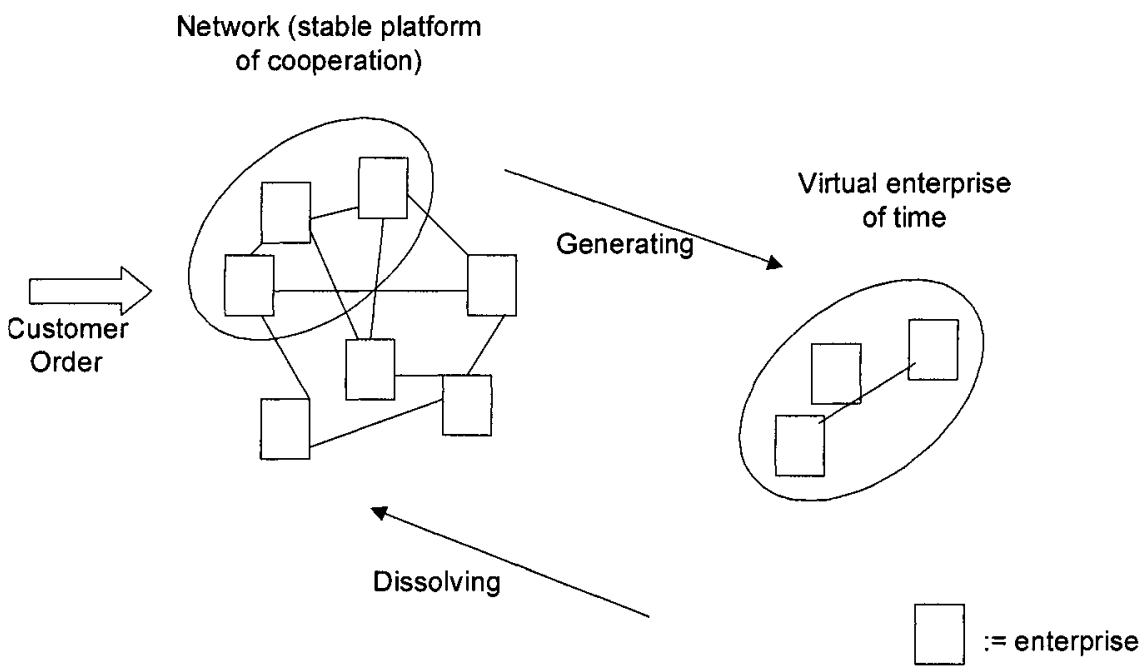

Figure 3. Generating a virtual enterprise from a stable network

\subsection{Learning to Work within Networked Enterprises}

Networked enterprises can be achieved through a cooperative learning using business processes crossing the border of individual enterprises, and leveraging knowledge and experiences across boundaries by learning how to empower People. Tasks of the workforce have to be enhanced and not restricted to well defined set of core competencies. That hampers the success of cross boundary teams. Perfectionism needs to be avoided as it acts as creativity brake. Three levels of learning have to be considered: 
- Learning level (1): within an enterprise: preparing cooperative work crossing the border of the individual enterprise through training of cooperative work of management and workforce within the individual enterprise.

- Learning level (2): within the stable networked enterprises: educating basic qualifications for tasks in networked enterprises; exchange of knowledge and experience crossing the border between professions and enterprises (dynamic modelling of business processes); scenarios of cooperation for learning.

- Learning level (3): concerning the virtual enterprise (real, border crossing business processes): considering actual business processes; dynamic assignment of competence respecting the actual demands of the market and the customer for quality, cost and delivery time; quick solving of occurring problems through direct cooperation of the involved personnel; the management level will be involved in problem solving if and only if solutions are not possible within the given frame.

After finishing the level (1), teams of members of management and workforce of networked enterprises will be set up for the levels (2) and (3). Personnel involved in the actual border crossing business process have to be informed on all details, have to understand all tasks and must be able to carry out all due tasks. The restrictions to tasks belonging to the core competence of the respective networked enterprise, where a team member is employed, hampers the success of a virtual enterprise. At least every involved person must have an overview of the sequences of the actual business process to make a cooperative work effective. The following learning goals are connected to the levels:

- independent thinking and flexible acting;

- knowledge and skill which extends across the profession, the department and the specific enterprise;

- cooperating within the specific enterprise and cross-border of enterprises in task related teams;

- thinking entrepreneurial and acting responsible on all levels of the enterprises;

- indicators for growth - enterprises within a global environment;

- flexible cooperation - working in virtual structures;

- quality management of networked and virtual enterprises, QM systems cross-border of enterprises;

- implementation and effective use of communication and information technology;

- logistics among cross-border of enterprises. 
This concept was used to establish and support a network of 10 metalprocessing enterprises in the surrounding of Plauen, Saxonia, Germany. The network was called "Maschinenbau Vogtland (MAVO)". The spiral of Figure 2 served as the learning model, first to promote cooperative work in individual enterprises and thereafter to foster the step from network to virtual enterprises.

Staff members of the Innovation Centre Plauen as external facilitators kept the process going (ERBE, KIM 1998). Other experiences with establishing networks are reported. The Berkshire Plastic Network, Pittsfield, MA, was established in 1986. It is a consortium of more than 30 independent companies, representing virtually every discipline in the design and production of moulds, components and plastic products. The mould-makers of the Berkshire region were short on qualified workers. Therefore they decided to launch an apprenticeship program. This fostered a trust building between the then involved small shops. Now the network is organised as a wheel with the members as spokes. If one spoke breaks the network will remain stable. The network runs a small office where customer requests come in. All network members get the information regarding the request, and they can bid to get the order, mostly together with part of other bidders, forming a virtual enterprise. One of the enterprises will serve as the contractor, the others are the subcontractors. The office with a president (an owner of one of the member enterprises) serves as a facilitator to keep the network stable.

\section{CONCLUSION}

The learning process proceeds in loops and passing one loop completely describes one complete action. Based on the experiences of the former loops, a learning process starts, which leads to a permanent development of not only a personal but also a collective mastery. Metaphorically speaking, the learning loops will move up like a helix. This process is only carried out by the individuals involved. But after implementing such a process, individuals may leave, the process will not collapse. This is the aim of the learning process within an enterprise, which combines the individual with the collective.

As was expected, apart from the Innovation Centre, also the participating university got a better understanding of requirements of small enterprises, because in its teaching contents and teaching structure it is often far away from economic needs in these enterprises. So far it was a goal to develop new forms of cooperation in continuing education.

The technical support of cooperative work in teams is insufficient until now. Criteria for structuring planning- and decision making- support usable by teams are missing. For teams of networked enterprises there is no techni- 
cal support at all. It should be analyzed if standardised communication- and information technology (internet, intranet, etc.) could be adapted for the specific needs of networked enterprises or if a customised technology has to be developed.

Missing is as well a structured help for the documentation of evaluated results of token decisions to support the learning process and to disseminate experiences. This can help to develop competence in teams.

\section{REFERENCES}

BOEKHOFF, H.; ERBE, H.-H.:

Organisationales Lernen: kritischer Erfolgsfaktor für virtuelle Unternehmen?

In: Industrie Management,

Berlin, 15(1999)6, pp. 13-16.

CAMARINHA-MATOS, L. M.; AFSARMANESH, H.:

Cooperative Systems. Challenges in Virtual Enterprises.

In: Proceedings Esprit project 22647, Prodnet II.

1999.

ERBE, H.-H.; KIM, J.:

Das Lernende Unternehmen, berufsbegleitende und berufsübergreifende Weiterbildung in

Fa. Modellbau Roth GmbH.

Internal Report.

TU Berlin, 1998.

ERBE, Heinz-Hermann:

Learning for an Agile Manufacturing.

In: Human Aspects in Production Management.

Eds.: ZÜLCH, Gert; STOWASSER, Sascha; JAGDEV, Harinder S.

Aachen: Shaker Verlag, 2003, pp. 267-273.

(esim - European Series in Industrial Management, Volume 5)

FREITAG, M.; WINKLER, I.:

Mechanisms of Coordination in Regional Networks.

In: Preprint 7th International Conference on Multi-Organizational Partnerships and

Cooperative Strategy.

Leuven, 2000.

GLANCE, N. J.; HUBERMAN, B. A.:

The outbreak of cooperation.

In: Journal of Mathematical Sociology,

London, 17(1993)4, pp. 281-302.

NULLMEIER, E.:

Personalentwicklung für informationstechnisch vernetzte Arbeit.

In: FH-Technik \& Wirtschaft-Magazin,

Berlin, 2000, pp. 141-144.

SCHUH, G.; MILLARG, K.; GÖRANSSON, A.:

Virtuelle Fabrik - Neue Marktchancen durch dynamische Netzwerke.

München: Carl Hanser Verlag, 1998. 


\section{SENGE, P.:}

The Fifth Discipline: the art and practice of the learning organization.

NewYork: Doubleday, 1990.

WATKINS, Karen E.; MARSICK, Victoria J.:

Sculpting the learning organization.

San Francisco, CA: Jossey-Bass Publishers, 1993.

WEBER, W. G.:

Kooperation in Organisationen unter arbeits- und sozialpsychologischern Gesichtspunkten

- vom individual-utilitaristischen zum prosozialen Handeln?

In: Kooperation in Unternehmen. Sonderband 1998 der Zeitschrift für Personalforschung. München: R. Hampp Verlag, 1998.

YORKS, L.; O'NEIL, J.; MARSICK, V. J.:

Action Learning.

In: Advances in Developing Human Resources.

Ed.: SWANSON, R.

Baton Rouge: Academy of Human Resource Development, 1999. 